\title{
Mapeamento de Informações Tecnológicas em Documentos de Patente: uso da borra de café na produção de biocombustíveis
}

\author{
Mapping Technological Information in Patent Documents: use of coffee \\ rubber in biofuel production
}

\author{
Michelle Cristina da Silva ${ }^{1}$ \\ Cassandra Carneiro de Medeiros ${ }^{1}$ \\ Douglas Alves Santos ${ }^{1}$ \\ Victor Pelaez ${ }^{1}$ \\ Fernanda Salvador Alves ${ }^{1}$ \\ Renato Milhomem de Oliveira Filho ${ }^{2}$ \\ ${ }^{1}$ Universidade Federal do Paraná, Curitiba, PR, Brasil \\ ${ }^{2}$ Instituto Federal de Ciências e Tecnologia de Goiás, Goiânia, GO, Brasil
}

\begin{abstract}
Resumo
O estudo teve por objetivo mapear informações tecnológicas contidas em documentos de patente relacionadas ao aproveitamento da borra de café como matéria-prima na produção de biocombustíveis. A metodologia do trabalho consistiu na busca de documentos de patente no Derwent Innovations Index, Instituto Nacional da Propriedade Industrial (INPI) e LATIPAT-ESPACENET, utilizando palavras-chave e códigos de Classificação Internacional de Patentes (IPC) e Classificação Cooperativa de Patentes (CPC), previamente identificados na revisão bibliográfica e patentária. Os resultados indicaram concentração das tecnologias na classe C10L-005 em estado sólido; revelam a Coreia do Sul, Japão e EUA como mercados em que há maior interesse comercial; sugerem que ainda não há maturidade tecnológica em âmbito industrial; e mostram que o desenvolvimento de biocombustível no Brasil tem sido impulsionado pelas políticas de governo.
\end{abstract}

Palavras-chave: Biocombustíveis. Borra de café. Patentes.

\begin{abstract}
The study aimed to map technological information contained in patent documents related to the use of coffee grounds as a raw material in the production of biofuels. The methodology of the work consisted of searching for patent documents in Derwent Innovations Index, National Institute of Industrial Property (INPI) and LATIPAT-ESPACENET, using keywords and codes of International Patent Classification (IPC) and Cooperative Patent Classification (CPC), previously identified in the bibliographic and patent review. The results indicated concentration of technologies in class C10L-005 in solid state; reveal South Korea, Japan and the US as markets in which there is greater commercial interest; suggest that there is no technological maturity at the industrial level yet; and show that biofuel development in Brazil has been driven by government policies.
\end{abstract}

Keywords: Biofuels. Coffee grounds. Patents.

Área Tecnológica: Prospecções Tecnológicas de Assuntos Específicos. 


\section{Introdução}

O Brasil destaca-se como produtor competitivo no mercado de commodities agrícolas $e$ cultura extrativa, posicionando-se como o segundo país exportador de alimentos em 2016 (FAO, 2018), ao mesmo tempo em que gera grandes quantidades de agrorresíduos. Tais resíduos detêm significativo potencial de serem transformados em combustíveis, energia e produtos químicos (FORSTER-CARNEIRO et al., 2013). Em paralelo, os sinais de esgotamento das reservas de combustível fóssil, base da matriz energética mundial (LIMA et al., 2008) têm motivado o aproveitamento de outras matérias-primas como fonte de energia, dentre as quais destacamos a borra de café em função do volume de resíduos gerados, bem como do seu poder calorífico.

O presente estudo buscou mapear tecnologias de aproveitamento da borra de café na produção de biocombustível, por meio da análise de documentos de patentes, utilizando as interfaces do Derwent Innovations Index, Instituto Nacional da Propriedade Industrial (INPI) e LATIPAT-ESPACENET. Para atender a esse objetivo geral, o texto está estruturado da seguinte forma: na seção 2 , é feita uma breve revisão bibliográfica sobre o potencial de aplicação da borra de café como biocombustível em um contexto de incentivo global ao uso de alternativas aos combustíveis fósseis; na seção 3, apresenta-se a metodologia de coleta de dados nas bases de patentes; na seção 4, apresentam-se os resultados em termos da evolução histórica dos depósitos de patentes em âmbito mundial, os principais países de origem dos depositantes, os principais códigos de identificação das tecnologias e os principais depositantes; e, na seção 5 , são feitas as considerações finais.

\subsection{A Borra de Café como Matéria-Prima para Geração de Biocombustível}

A crescente demanda mundial por energia associada à preocupação com o impacto das mudanças climáticas e ao aumento dos preços do petróleo têm reforçado o interesse na utilização de combustíveis renováveis (SILVA; SAKATSUME, 2007; SALLET; ALVIM, 2011; BRANCO, 2009). Teixeira et al. (2007) argumentam que a biomassa é a tendência estratégica como substituta do petróleo. Já Silva (2011) demonstra que a utilização de biomassa pode promover uma redução de até $86 \%$ dos gases de efeito estufa, quando comparada com os gases gerados pelo petróleo.

O Acordo de Paris ${ }^{1}$, por sua vez, intensificou o compromisso de 195 países em prol da redução dos gases de efeito estufa. Entretanto, segundo Caseiro (2011), a produção de combustíveis alternativos ainda se encontra espacialmente concentrada, haja vista que apenas seis países concentram $89 \%$ dessa produção em escala global. O Brasil aderiu ao Acordo de Paris em 2016 e se comprometeu a reduzir, até 2025, as emissões desses gases em 37\%, e em 43\% até 2030, em relação aos níveis de 2005 (quando entrou em vigor o Protocolo de Kyoto) ${ }^{2}$. Neste cenário, o Governo Brasileiro criou a Política Nacional de Biocombustíveis (RenovaBio), pela Lei n. 13.576/2017, com o objetivo de expandir a produção de biocombustíveis no país e de viabilizar o alcance de seus compromissos internacionais.

Maricato, Noronha e Fujino (2008) argumentam que, apesar de o biodiesel ser promissor diante das limitadas reservas de combustível fóssil, o fato de o Brasil possuir uma extensa fron-

\footnotetext{
${ }^{1}$ O Acordo de Paris (2015) busca fortalecer a resposta global à ameaça da mudança climática e reforçar a capacidade dos países para lidar com os impactos decorrentes dessas mudanças (Ministério do Meio Ambiente, 2018).

${ }^{2}$ O Protocolo de Kyoto (1997) é o principal acordo sobre mudanças climáticas e estabelece metas para a redução de emissões de CO2 (resultante da queima de combustíveis fósseis), na atmosfera. O CO2 (dióxido de carbono) é um dos principais gases de efeito estufa (SALLET; ALVIM, 2011).
} 
teira agrícola não é suficiente. É fundamental, outrossim, o domínio tecnológico na área. Dias, Vian e Grin (2008) destacam que a geração de inovações tecnológicas relacionadas à cadeia produtiva de agroenergia deve ser uma meta ambiciosa para o Brasil.

Caseiro (2011) ressalta a necessidade de se diversificar as matérias-primas utilizadas na geração de biocombustíveis, em virtude dos impactos ambientais derivados do cultivo, tais como desflorestação, erosão dos solos, perda de biodiversidade, contaminação dos solos e da água, e sobre-exploração dos recursos hídricos e das áreas agrícolas. Para Mendes e Costa (2010), o grande desafio para o ramo de biodiesel brasileiro é o de se desassociar da cadeia produtiva da soja, mediante o emprego de matéria-prima de alta produtividade que não seja alimento, e uma das dificuldades enfrentadas é a de exportar o biodiesel nacional para os grandes consumidores internacionais, principalmente a União Europeia (UE).

Em paralelo, sendo o café uma das bebidas mais consumidas no mundo, com uma produção de grãos estimada em cerca de 165 milhões de sacas em 2018-2019 (ABIC, 2019), grandes quantidades de resíduos são geradas no setor cafeeiro, os quais são tóxicos e resultam em sérios problemas ambientais (MUSSATO et al., 2011). Desde o início dos anos 1990, Vegro e Carvalho (1994) já indicavam a necessidade de se dar uma destinação para esses resíduos, em função da crescente preocupação com o impacto ambiental gerado.

A borra produzida na indústria de café solúvel é um resíduo cujo aproveitamento tem sido objeto de pesquisa. Estima-se que 34 toneladas de borra de café são produzidas por dia, o que representa um potencial para a produção de 1,5 toneladas de óleo com emprego como biocombustível (CUNHA et al., 2018).

Almeida e Sparagino (2012) compararam o poder calorífico de uma série de resíduos agrícolas, dentre os quais a borra de café, que apresenta o maior valor $(5.960 \mathrm{kcal} / \mathrm{kg}$ ) (Tabela 1). Esse elevado poder calorífico indica o grande potencial de uso da borra de café como uma fonte de energia alternativa ao uso de combustíveis fósseis, em um cenário de transição da matriz energética em escala global.

Tabela 1 - Poder calorífico de diversos resíduos agrícolas

$\begin{array}{ccc}\text { Material } & \text { Poder Calorífico (KCAL/KG) } & \text { Autor } \\ \text { Borra de café } & 5960 & \text { Anon [23] } \\ \text { Madeira } & 5450 & \text { Anon [23] } \\ \text { Fibra de coco } & 4707 & \text { Kumar et al. [22] } \\ \text { Caules de juta } & 4619 & \text { Kumar et al. [22] } \\ \text { Bagaço de cana-de-açucar } & 4470,59-4600 & \text { Anon [23] } \\ \text { Palha de trigo } & 4185 & \text { Kumar et al. [22] } \\ \text { Casca de arroz } & 3805 & \text { Kumar et al. [22] } \\ \text { Espiga de milho } & 3804 & \text { Kumar et al. [22] } \\ \text { Galhos de algodoeiro } & 3750 & \text { Kumar et al. [22] }\end{array}$

Fonte: Adaptada de Almeida e Sparagino (2012)

Estima-se que, no Brasil, são produzidas 209.280 toneladas de lixo diariamente, das quais $90,4 \%$ são coletadas e apenas $58,26 \%$ destinadas a aterros sanitários, ficando o restante en- 
caminhado a lixões ou aterros controlados (THODE FILHO et al., 2015). O café é um produto que depois de utilizado, gera resíduos (borra de café), cujo destino final é tradicionalmente o aterro. Devido à ausência de um sistema de gerenciamento de coletas apropriado, alguns países preocuparam-se com a gestão de resíduos, resultando em leis que responsabilizam os produtores dos resíduos pela recuperação dos produtos que eles produzem quando chegam ao fim de sua vida útil. Nesse sentido, o Brasil, com a Lei n. 12.305/2010, estabeleceu a política nacional de resíduos sólidos, onde os produtores, importadores e comerciantes são considerados corresponsáveis pelos impactos ambientais de produção, transporte, consumo e descarte de produtos (CORRÊA et al., 2013).

O fato de o Brasil ser o maior produtor mundial de café (FAOSTAT, 2018), da ordem de 3,7 milhões de toneladas (CONAB, 2018), e o segundo maior mercado consumidor, estimado em 1,3 milhão de toneladas em 2018 (ABIC, 2018), revela o grande potencial associado à geração e à difusão de tecnologias para aproveitamento de resíduos do café, inclusive a borra, na geração de biocombustíveis.

A cadeia produtiva do café identifica as principais etapas de processamento e consumo do grão (Figura 1). Os torrefadores são os principais atores da cadeia, tanto por sua capacidade de agregar valor quanto de definir a qualidade do produto, pois as características organolépticas do café são determinadas, em grande parte, no processo de torrefação, que geralmente inclui a mistura de diferentes variedades do grão (KHODAKARAMI et al., 2016).

Cabe ressaltar que a etapa de torrefação e moagem está inserida na indústria do café solúvel. Esta apresenta o maior potencial de aproveitamento da borra de café por ser o principal subproduto de sua atividade de processamento. O consumo de café solúvel representa um mercado em expansão no qual as vendas globais foram da ordem de US $\$ 28$ bilhões em 2016, com uma estimativa de crescimento de 4,8\% ao ano, podendo atingir US\$ 42,5 bilhões em 2025 (ABICS, 2017). 
Figura 1 - Representação da cadeia do café brasileiro

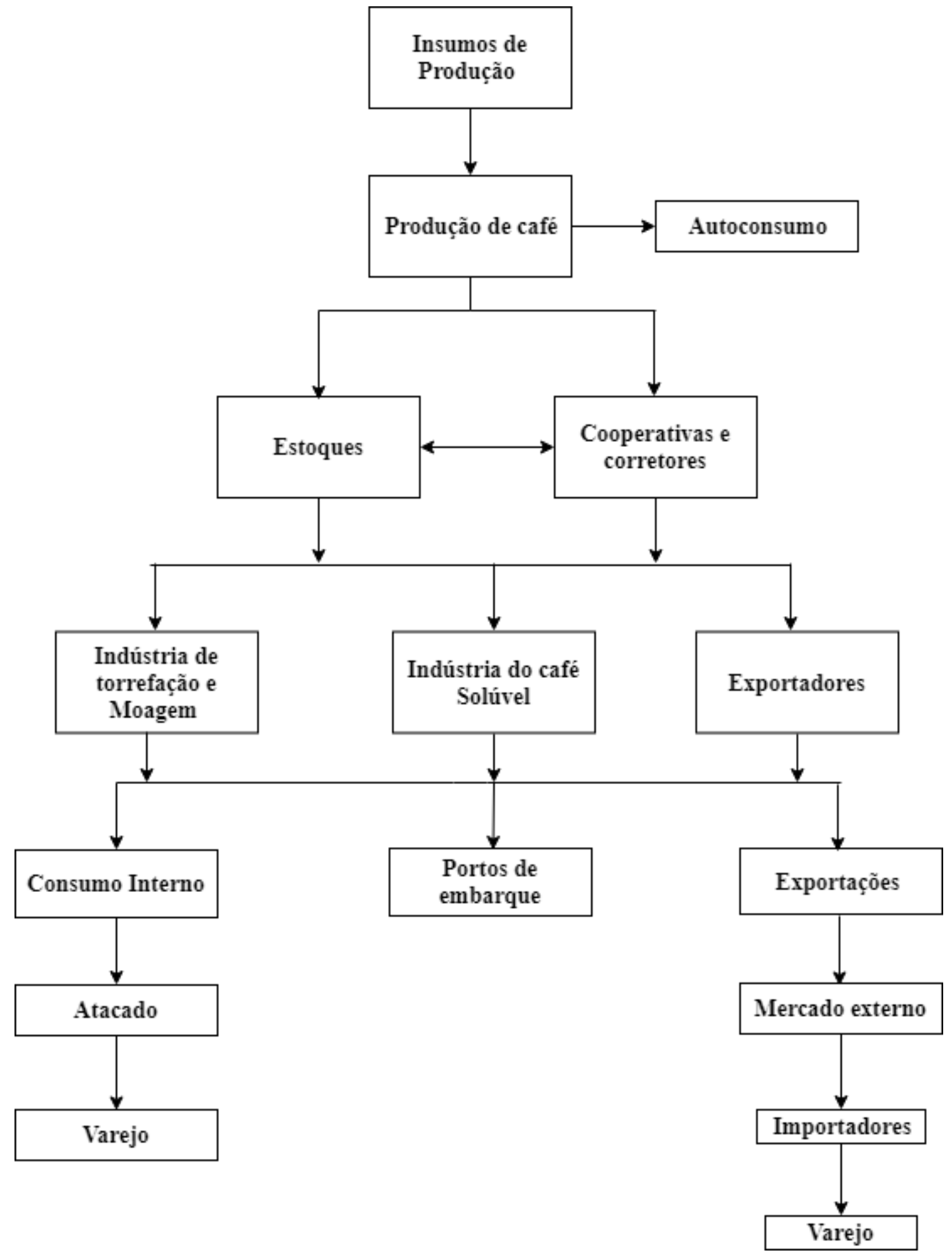

Fonte: Ponciano (1995)

A revisão bibliográfica conduzida neste trabalho identificou diversas pesquisas realizadas em escala laboratorial, as quais corroboraram a viabilidade técnica de obtenção de biocombustíveis, tanto para a produção de óleos e ésteres quanto para a produção de briquetes, a partir da borra de café. Santos e Haraguchi (2016) comentaram que os grãos de café contêm aproximadamente de 10 a 15\% de lipídeos, dos quais $80-95 \%$ correspondem a glicerídeos, e que ao expor o óleo (triglicerídeos) à presença de álcool e catalisador em um processo de 
transesterificação, há formação de éster e glicerol, os quais possuem características muito semelhantes ao do diesel convencional. Já no estudo de Page, Arruda e Freitas (2017) ficou demonstrado que o rendimento do extrato etanólico bruto obtido a partir de borra de café foi superior ao rendimento do éter. A pesquisa realizada por Figini et al. (2017) observou que a borra residual de café apresenta elevado conteúdo de óleo (12-20\%), próximo ao obtido em fontes convencionais como a soja (20\%). Primaz (2018), por sua vez, demonstrou que a borra residual do café e a semente de algodão são resíduos com alto conteúdo lignocelulósico, o que os torna atrativos para aplicação em tecnologias termoquímicas como a pirólise, que consiste na conversão de biomassa em energia e produtos químicos de valor agregado.

Estudo realizado por Jang et al. (2015) aponta que a utilização da borra do café, por meio da tecnologia de célula de combustível de carbono em alta temperatura, apresenta um potencial de $87.2 \mathrm{~mW} \mathrm{~cm}^{2}$, que é quase duas vezes maior que o negro fumo ${ }^{3}\left(46.3 \mathrm{~mW} \mathrm{~cm}^{2}\right)$ na produção de energia elétrica em células a combustível. Pesquisadores do Instituto Gwangju de Ciência e Tecnologia da Coreia do Sul mostraram que a borra do café, após a secagem, possui um potencial de combustão maior (em $88 \%$ ) do que fontes de carbono de melhor qualidade, como o carvão preto, os quais geralmente são usados como combustível. Além disso, produz pequena quantidade de cinzas depois de gerar a eletricidade (FUEL CELLS BULLETIN, 2015).

Considerando a importância dos documentos patentários na identificação de soluções e tendências tecnológicas, bem como na construção de indicadores temáticos, vários estudos foram realizados com o objetivo de identificar o desenvolvimento tecnológico relacionado a biocombustíveis. No geral, tais pesquisas abordam (i) a análise da produção e do consumo de biocombustíveis no mundo, (ii) os esforços empreendidos para uso de diferentes materiais na geração de biocombustíveis, (iii) as potencialidades e a evolução dessas tecnologias, e (iv) o levantamento de patentes na área de biocombustíveis. Outrossim, apontam a importância de os países e empresas continuarem investigando e aprimorando tecnologias nessa área de interesse. Entretanto, a literatura carece de uma busca de documentos patentários voltados especificamente à utilização da borra de café na geração de biocombustíveis.

\section{Metodologia}

No primeiro momento, realizou-se uma análise bibliográfica para classificar e parametrizar as características e definições da pesquisa. Assim sendo, a prospecção tecnológica realizada em documentos de patentes contemplou aspectos qualitativos e quantitativos, uma vez que houve a necessidade de análise e interpretação de contextos, informações e fatos, como também a organização, caracterização e interpretação de dados numéricos. Em paralelo à parametrização da pesquisa, realizaram-se análises bibliográficas em documentos científicos relacionados à tecnologia de biocombustível derivado da borra de café.

A Figura 2 ilustra o diagrama de blocos da metodologia utilizada. Realizou-se a busca por palavras-chave e por códigos da Classificação Internacional de Patentes (IPC) e da Classificação Cooperativa de Patentes (CPC). A linha tracejada da Figura 2 indica o movimento de retomada da análise bibliográfica para viabilizar e ajustar a extração de palavras-chave, IPC e CPC.

${ }^{3}$ Negro fumo é um material que consiste em composição amorfa de partículas de carbono contendo dispersão coloidal de partículas muito finas aglutinadas (KUNRATH, K. et al, 2012). 
Foram realizadas buscas no Derwent Innovations Index, no INPI e no LATIPAT. A escolha dessas bases de dados deveu-se à acessibilidade, à confiabilidade dos dados e à amplitude de cobertura temporal e territorial das publicações. Ademais, considerando que países de língua espanhola estão entre os principais produtores de café, a seleção dessas bases patentárias, complementares em sua abrangência, buscou assegurar a recuperação de tecnologias desenvolvidas nesses países, bem como para exploração comercial nesses mercados.

Figura 2 - Diagrama de blocos com metodologia aplicada

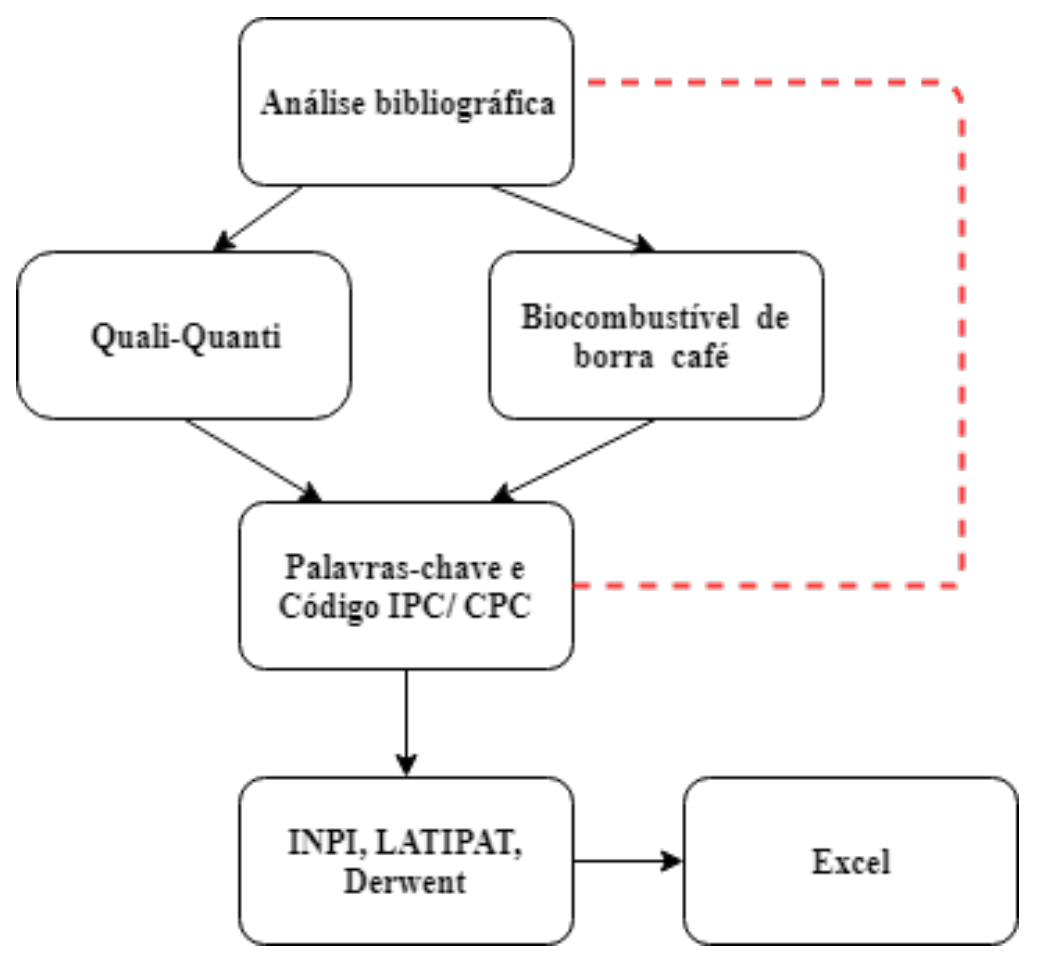

Fonte: Elaborada pelos autores deste artigo (2019)

A coleta de dados nas referidas bases foi realizada no dia 22 de novembro de 2018 . Utilizou-se como estratégia de busca a combinação dos prefixos "caf", "diese", "combust" e da palavra "coffee", como indicado no Quadro 1 (nos idiomas inglês, português e espanhol), nos campos de buscas avançadas, das respectivas bases de dados.

Quadro 1 - Palavras-chave e termos utilizados nas buscas patentárias relativas ao uso de borra de café na produção de biocombustíveis

\begin{tabular}{|c|c|c|c|c|c|}
\hline PALAVRAS-CHAVES & TERMOS & & & \\
\hline caf* & OR & coffe* & AND & diese* & (caf* OR coffe*) AND diese* \\
\hline caf* & OR & coffe* & AND & bio?diese* & (caf* OR coffe*) AND bio?diese* \\
\hline caf* & OR & coffe* & AND & combust* $^{*}$ & (caf* OR coffe*) AND combust* \\
\hline caf* & OR & coffe* & AND & bio?combust* & (caf* OR coffe*) AND bio?combust* \\
\hline caf* & OR & coffe* & AND & Fuel & (caf*OR coffe)* AND fuel \\
\hline caf* & OR & coffe* & AND & Ester & (caf*OR coffe)* AND ester \\
\hline caf* & OR & coffe* & AND & bio?oil & (caf*OR coffe)* AND bio?oil \\
\hline
\end{tabular}

Fonte: Elaborado pelos autores deste artigo (2019) 
Essa busca preliminar em documentos de patentes permitiu identificar sete códigos IPC e $\mathrm{CPC}$ que estão diretamente relacionados à tecnologia de produção de biocombustível derivado da borra de café, conforme indicado no Quadro 2.

Quadro 2 - Códigos de patentes relativos à produção de biocombustível derivado da borra de café

\begin{tabular}{|c|c|}
\hline Código & DESCRIÇÃo \\
\hline $\mathrm{C} 07 \mathrm{C} 51^{*}$ & Preparação de ácidos carboxílicos ou de seus sais, haletos ou anidridos \\
\hline C10B53* & $\begin{array}{l}\text { Destilação destrutiva, especialmente adaptada a determinadas matérias- } \\
\text { primas sólidas ou matérias-primas sólidas de forma especial }\end{array}$ \\
\hline C10G* & $\begin{array}{l}\text { Recuperação de óleos hidrocarbonetos de óleo de xisto, areia oleaginosa ou gases; refino de } \\
\text { misturas principalmente consistindo de hidrocarboneto; reforma de nafta; ceras minerais }\end{array}$ \\
\hline C10L* & $\begin{array}{l}\text { Combustíveis não incluídos em outro local; gás natural; gás natural de síntético } \\
\text { obtido por processos não abrangidos pelas subclasses C10g ou C10k; gás liquefeito } \\
\text { de petróleo; uso de aditivos em combustíveis ou ao fogo; acendedores de fogo }\end{array}$ \\
\hline $\mathrm{C} 11 \mathrm{~B} 1 *$ & $\begin{array}{l}\text { Produção, p. ex. por compressão de matérias-primas ou por extração a partir de } \\
\text { substancias de rejeitos, refinação ou preservação de óleos, substancias graxas, p. ex. } \\
\text { lanolina, óleos graxos ou ceras; óleos essenciais; perfumes (óleos secantes c09f) }\end{array}$ \\
\hline $\mathrm{C} 11 \mathrm{C} 3 *$ & $\begin{array}{l}\text { Gorduras, óleos ou ácidos graxos resultantes da modificação química } \\
\text { de gorduras, óleos, ou ácidos graxos, p. ex. por ozonólise }\end{array}$ \\
\hline Y02E50* & Tecnologias para a produção de combustível de origem não fóssil \\
\hline
\end{tabular}

Fonte: Elaborado pelos autores deste artigo com base na classificação IPC (2019)

Utilizou-se a ferramenta Excel para a criação de banco de dados exportado da base Derwent Innovations Index, a qual gerou arquivo com os campos da patente (número da patente, resumo, autores, etc.). Realizaram-se leituras dos resumos de todos os documentos de patentes exportados para a plataforma Excel, de forma a classificar as tecnologias e excluir dados duplicados ou não pertinentes ao objeto de pesquisa.

No que se refere às limitações deste trabalho, pode-se verificar que a busca não recuperou pedidos de patente em período de sigilo, o que representa uma defasagem tecnológica de dezoito meses. Além disso, as bases do INPI e do Derwent Innovations Index não permitem buscas usando o CPC, mas apenas o IPC. Verificou-se também que a base do INPI não dispõe de consulta por palavras-chave no corpo do documento, mas apenas no título ou no resumo, o que restringe o levantamento das informações patentárias.

\section{Resultados e Discussão}

Considerando-se que as análises por indicadores são úteis para promover transferências de tecnologia, gerar investimentos em inovação e fomentar a competitividade industrial, os resultados desta pesquisa foram estruturados de acordo com: i) a evolução da quantidade de depósitos de patente; ii) os mercados de interesse comercial, por meio da identificação dos países nos quais foram depositados os pedidos; iii) o perfil dos depositantes, em termos da natureza jurídica; e iv) as áreas tecnológicas de maior incidência de depósitos de patentes. 
Foram recuperados inicialmente 534 documentos de patente no Derwent Innovations Index, no INPI e no LATIPAT. Após a exclusão de documentos duplicados e não pertinentes, restaram 99 processos de patente, conforme especificado na Tabela 2.

Tabela 2 - Dados patentários recuperados das bases DERWENT, INPI e LATIPAT, relativos ao uso de borra de café na produção de biocombustíveis

\begin{tabular}{ccccc} 
& DERWENT & INPI & LATIPAT & Total \\
Número de documentos recuperados & 315 & 1 & 218 & 534 \\
Número de documentos após refinamento & 94 & 0 & 5 & 99 \\
\hline
\end{tabular}

Fonte: Elaborado pelos autores deste artigo com base nos dados obtidos no Derwent, INPI e LATIPAT (2019)

Avaliando-se os documentos recuperados e tratados nesse levantamento, observou-se que o primeiro documento de patente contido nas referidas bases remonta com 1979, advindo do Japão. Isso representa uma linha cronológica de análise de dados de 39 anos em que se tem buscado o emprego da borra de café na geração de biocombustíveis. No presente estudo, foi considerada a data de depósito dos documentos de patentes exportados para o Excel.

\subsection{Evolução dos Depósitos de Patente}

O levantamento patentário identificou, no período de 1979 a 2005, uma média anual de dois pedidos de patentes. A partir de 2005, com a entrada em vigor do Protocolo de Kyoto, verificou-se a expansão dos pedidos de patentes desse tipo de tecnologia, seguido de um declínio nos anos de 2008 a 2009, conforme indica o Gráfico 1. Registre-se que, em 2013, houve uma crise na indústria cafeeira no Brasil, decorrente da alta dos custos de produção, queda dos preços da saca de café e redução do consumo de café no país (LOPES e ALVES, 2015). Sendo o Brasil o maior produtor mundial à época, isso pode ter influenciado negativamente o ritmo de pedidos de patentes, como observado em 2014.

Gráfico 1 - Evolução do número de depósitos de patentes, em âmbito mundial, relativas ao uso de borra de café na produção de biocombustíveis, no período de 1979 a 2018

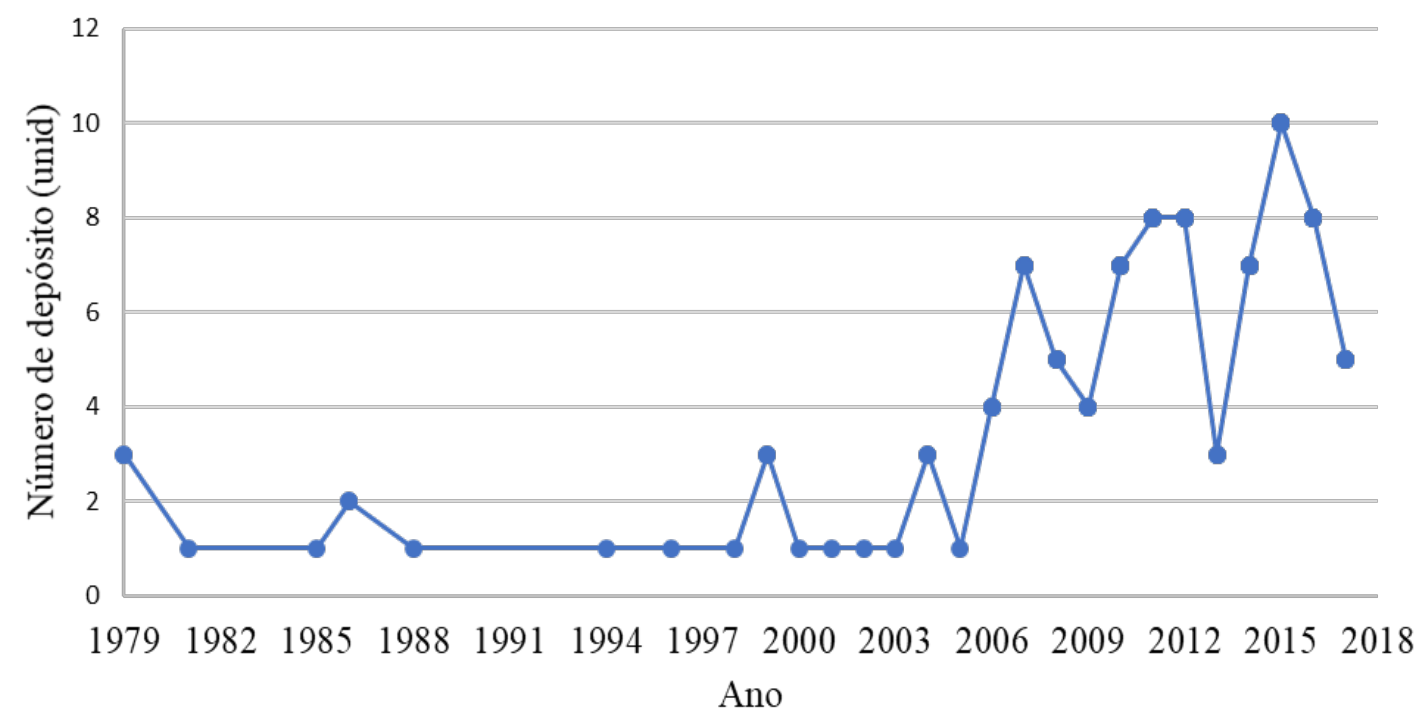

Fonte: Elaborado pelos autores deste artigo com base nos dados obtidos no Derwent, INPI e LATIPAT (2019) 


\subsection{Mercados de Interesse Comercial}

Coreia do Sul, Japão e EUA destacam-se como países em que há maior interesse para exploração comercial da tecnologia, com 34, 24, e 24 depósitos de patentes, respectivamente, no período 1979-2018 (Gráfico 2).

Gráfico 2 - Países com maior número de depósitos de patentes relativas ao uso de borra de café na produção de biocombustíveis, no período de 1979 a 2018

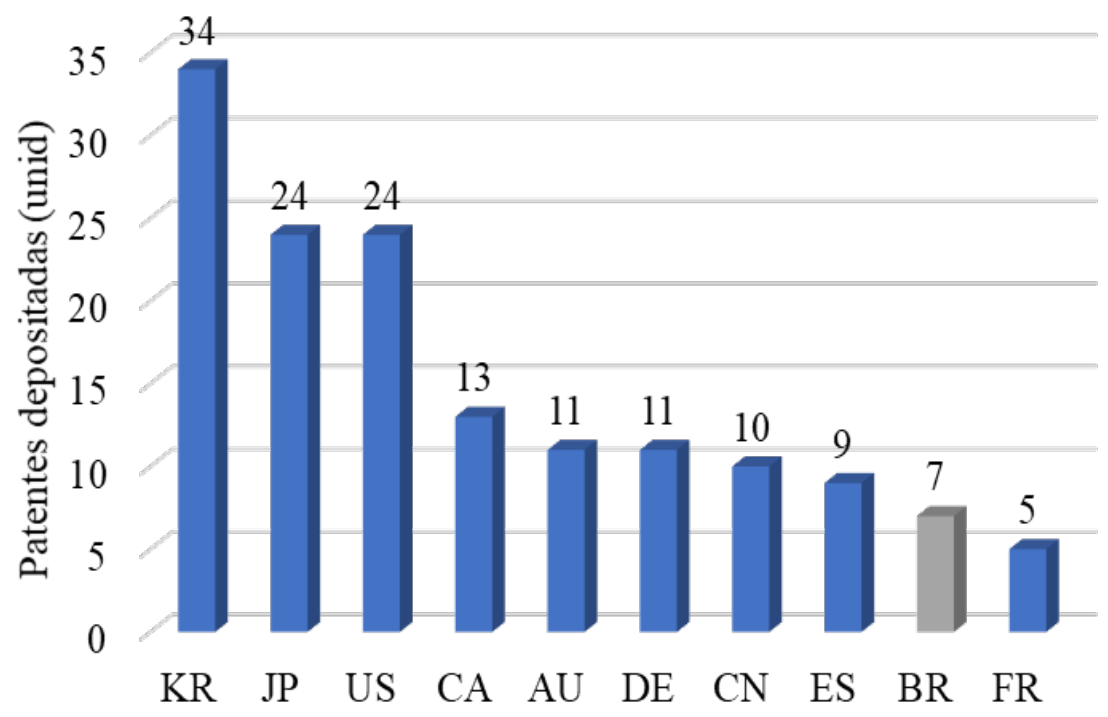

Fonte: Elaborado pelos autores deste artigo com base nos dados obtidos no Derwent, INPI e LATIPAT (2019)

No caso da Coreia do Sul, tem havido a implementação de incentivos governamentais para a redução da dependência dos combustíveis fósseis por meio da ampliação do uso de biocombustíveis de segunda e de terceira geração (MASIERO, 2008). Em tal cenário, o aumento do consumo de café no país asiático, nas últimas décadas, e a consequente geração de borra despertaram o interesse no aproveitamento desse resíduo. Ressalte-se que, como a Coreia do Sul não dispõe das condições climáticas adequadas ao cultivo do café, o Brasil tem sido o seu principal fornecedor.

Os EUA encontram-se entre os maiores produtores de commodities industriais, é fornecedor de produtos agrícolas e líder mundial no desenvolvimento de biocombustíveis, com destaque para a biomassa (SU et al., 2015). Os autores ainda mencionam que a força motriz dos EUA para o desenvolvimento de biomassa é guiada pelas metas de: i) reduzir a dependência de importação de petróleo; ii) criar oportunidade de emprego e desenvolver a agricultura; iii) promover o desenvolvimento de baixo carbono e economia sustentável; e iv) explorar novas tecnologias para propiciar fontes de energias alternativas. O incentivo da política governamental, através da promulgação de leis e regulamentos relacionados à energia, incluindo políticas fiscais e financeiras, apoios e garantias de empréstimos para pesquisa e desenvolvimento (P\&D) de biocombustíveis derivados de biomassa, possibilitou o crescimento na produção de biocombustível no país.

Por sua vez, o governo do Japão tem promovido o uso de energias renováveis na produção e utilização de biocombustíveis, e incentivado $\mathrm{P} \& \mathrm{D}$ para a segunda geração de biocombustíveis 
e o estabelecimento de padrões de produção sustentáveis (KOIZUMI, 2013). Para promover o desenvolvimento de biocombustíveis, o país adotou estratégias e planos nacionais, como a Estratégia Nippon da Biomassa, o plano de realização do Protocolo Kyoto e a Estratégia Nacional para a Energia. Tais estratégias conduziram iniciativas de redução de impostos sobre importação, apoio financeiro e fiscal para os produtores de matérias-primas, e apoio a projetos-piloto de desenvolvimento de biocombustíveis (MATSUMOTO et al., 2009).

A China tem sido um importante player no investimento e promoção de energia, por seu interesse em desenvolver hidrelétrica, solar e eólica, bioenergia e biocombustíveis (DYK et al., 2016). Mesmo sendo um mercado promissor no consumo do café, com aumento de 300 mil sacas em 2008/2009 para 3,8 milhões em 2017/2018 (CONSÓRCIO, 2018), a China ainda não se encontra entre os principais mercados para comercialização dessa tecnologia de biocombustível, indicando dez depósitos de pedidos de patentes, no período 1989-2018. Em decorrência do rápido aumento do consumo de petróleo, a projeção da International Energy Agency (IEA) informa que cerca de $75 \%$ do consumo de petróleo da China será importado até 2030 (QIU et al., 2012). Os autores também mencionam que a China fez progressos consideráveis em utilização de energia renovável, incluindo biocombustíveis líquidos (milho, mandioca e sorgo), tornando-se o quarto maior produtor do mundo em biocombustível líquido depois dos EUA, Brasil e UE. Isso pode indicar o desinteresse do país na tecnologia por biocombustível de borra de café.

Já o Brasil assume a nona posição dentre os países em que há interesse comercial, com sete depósitos de patentes, entre os anos de 1979 a 2015 (Tabela 3). O documento patentário obtido em 1979 possivelmente resulta das crises de petróleo, em 1973/74 e 1979/80 (FERREIRA et al., 1999). Em resposta ao desabastecimento de petróleo, renovou-se no país o interesse pela busca de fontes alternativas. O governo federal criou, nesse período, o Plano de Produção de Óleos Vegetais para Fins Energéticos (PRO-ÓLEO), elaborado pela Comissão Nacional de Energia, por meio da Resolução n. 007/1980, que previa a mistura de 30\% de óleo vegetal ao óleo diesel (SUAREZ et al., 2007). Com a assinatura do Protocolo de Kyoto em 1997, o governo brasileiro retomou as discussões e estudos sobre o uso do biodiesel, lançando em 2004, o Programa Nacional de Produção e Uso de Biodiesel (PNPB), com o objetivo de garantir a produção economicamente viável do biocombustível (SUAREZ et al., 2007). A principal ação legal do PNPB foi a introdução de biocombustíveis derivados de óleos e gorduras na matriz energética brasileira, por meio da Lei n. 11.097/2005. Tal contexto, associado ao fato de o governo ter assumido a coordenação de políticas públicas de apoio à atividade cafeeira na década de 1990, após a extinção do Instituto Brasileiro do Café (IBC) em 1989, pode ter motivado os pedidos de patente depositados no Brasil entre 1989 a 2002.

No que se refere ao processo de patente de 2010, verificou-se a obrigatoriedade da mistura do biodiesel do óleo vegetal ao diesel em 2\% (B2) a partir de 2008; em julho de 2009, entra no mercado a obrigatoriedade da mistura do biodiesel em 4\% (B4) e, em janeiro de 2010, em 5\% (B5) (TÁVORA, 2011). Esse estímulo de combustível renovável derivado de óleos vegetais possivelmente influenciou a entrada do documento de 2010 no Brasil. Já os documentos de 2015 podem estar associados à participação do Brasil na Conferência das Nações Unidas sobre Mudanças Climáticas em 2015, em que a meta para o Brasil era aumentar a participação de $18 \%$ de bioenergia na matriz energética (DENNY, 2016). 
Cabe observar que, dos sete depósitos de patentes efetuados no Brasil no período consultado, seis foram realizados via Tratado de Cooperação de Patentes ( $\mathrm{PCT}^{4}$ ), sendo três pedidos oriundos dos Estados Unidos, um da Suíça, um do Canadá e um da Coreia do Sul (Tabela 3).

Tabela 3 - Informações relativas aos documentos patentários depositados no Brasil

\begin{tabular}{cccc} 
Depositado no BR & Data de Prioridade PCT & Origem & Perfil do de depositante \\
1979 & -- & Brasil & Pessoa física \\
1989 & 1988 & Suíça & Pessoa física \\
2000 & 1999 & Canadá & Pessoa física \\
2002 & 2002 & Estados Unidos & Pessoa física \\
2010 & 2009 & Estados Unidos & Pessoa jurídica \\
2015 & 2014 & Estados Unidos & Pessoa jurídica \\
2015 & 2015 & Coreia do Sul & Pessoa jurídica \\
\hline
\end{tabular}

Fonte: Elaborado pelos autores deste artigo com base nos dados obtidos no Derwent, INPI e LATIPAT (2019)

Apesar de o Brasil acumular uma experiência no âmbito da produção e uso de biocombustíveis (SILVA; SAKATSUME, 2007) e de desenvolver o maior programa de pesquisas em café do mundo, por meio do Consórcio Pesquisa Café, rede integrada de 45 instituições brasileiras de pesquisa (DURÁN et al., 2017), faz-se necessária a implementação articulada de políticas públicas que viabilizem a produção de combustíveis a partir de fontes renováveis.

Para Melo (2018), a Política Nacional de Biocombustíveis (RenovaBio), implementada em 2017 com objetivo de desenvolver todos os tipos de biocombustíveis no Brasil, em consonância com os pressupostos de sustentabilidade do Acordo de Paris, diferencia-se de outras políticas por não visar a criação de impostos; ao contrário, busca estimular a concorrência com combustíveis fósseis, de forma a garantir qualidade e preço para os consumidores. Roitman (2019) explica que as medidas adotadas no Brasil até o momento basearam-se apenas na diferenciação tributária entre combustíveis fósseis e renováveis, e comenta que o RenovaBio, inovador no Brasil, teve como fonte de inspiração diversas iniciativas internacionais em vigor há mais de oito anos, entre elas o Renewable Fuel Standard (RFS), dos Estados Unidos, o Low Carbon Fuel Standard (LCFS), da Califórnia, e o Renewable Energy Directive (RED), da União Europeia.

\subsection{Perfil dos Principais Depositantes}

Dos 99 documentos de patentes identificados, foram contabilizados 135 depositantes (considerando-se cotitulares), dentre pessoas físicas e jurídicas, provenientes de diferentes países. O Gráfico 3 indica os principais depositantes, com destaque para a empresa sul-coreana CE CO LTD, da área de negócios ambientais, com quatro documentos de patentes, a empresa canadense, Future Weste Management, do segmento de gerenciamento de resíduos, o depositante canadense independente Rodney K. Sprules e a empresa Java Logg Global Corp (sediada em Barbados), com três pedidos cada. Fato pertinente a destacar é que documentos de patentes 
de Rodney K. Sprules, contendo tecnologias relacionadas à composição de combustível à base de café, tiveram sua titularidade transferida para outras empresas, dentre as quais a Java Logg Global.

Cabe também mencionar que a empresa sul-coreana CE CO LTD consta como depositante de um dos sete processos patentários requeridos no Brasil.

Gráfico 3 - Principais depositantes identificados nas buscas patentárias no Derwent, INPI e LATIPAT, relativas ao uso de borra de café na produção de biocombustíveis, no período de 1979 a 2018

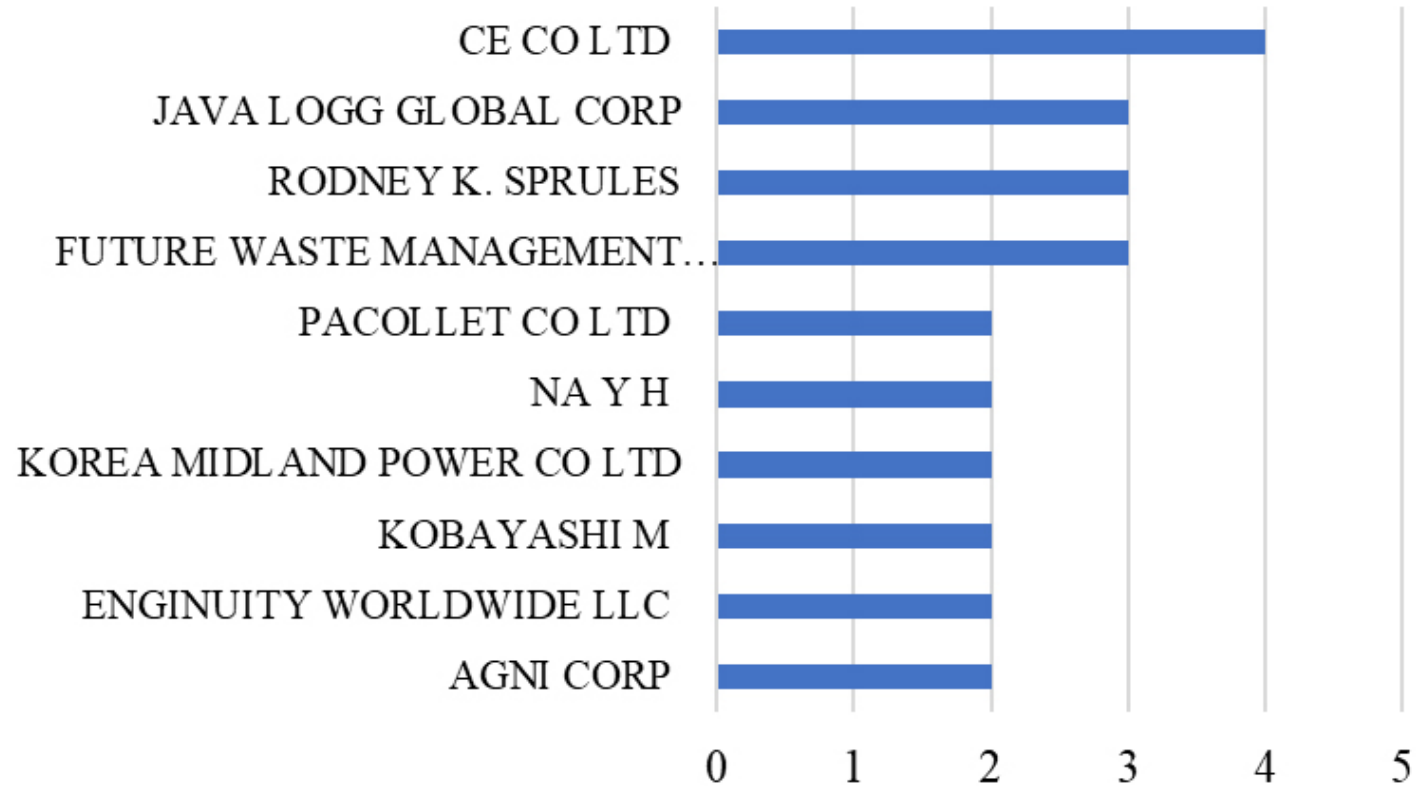

Fonte: Elaborado pelos autores deste artigo com base nos dados obtidos no Derwent, INPI e LATIPAT (2019)

\section{4 Áreas de Interesse no Desenvolvimento de Tecnologias}

O Gráfico 4 apresenta os códigos de Classificação Internacional de Patentes de maior incidência, nos quais se concentra o desenvolvimento tecnológico dos documentos recuperados, com significativo destaque para a classe C10L-005, presente em 65\% documentos. Em seguida, os códigos C10L-001 em 9\% e o B09B-003, que não estava definido nos parâmetros da pesquisa, mas que surgiu em $7 \%$ dos documentos. A classe de C10L é o grupo que refere à área de combustíveis sólidos produzidos pela solidificação de combustíveis fluidos para briquetes. Já a classe B09B contempla tecnologias de eliminação de resíduos, onde o subgrupo B09B-003/00 é caracterizado por destruição de lixo sólido ou transformação de lixo sólido em algo útil ou inofensivo. Como a biomassa proveniente de resíduos, plantas, descartes de lavoura e outros pode ser utilizada para geração de calor ou de energia elétrica, ou transformada em bicombustíveis sólidos, líquidos ou gasosos (CAVALCANTI et al., 2015), as propriedades físico-químicas da borra de café associadas ao grande volume de borra produzido no mundo incentivam o aproveitamento da biomassa de borra em forma de briquetes. 
Gráfico 4 - Número de publicações de patente por códigos de classificação internacional de patentes, relativas ao uso de borra de café na produção de biocombustíveis, no período de 1979 a 2018

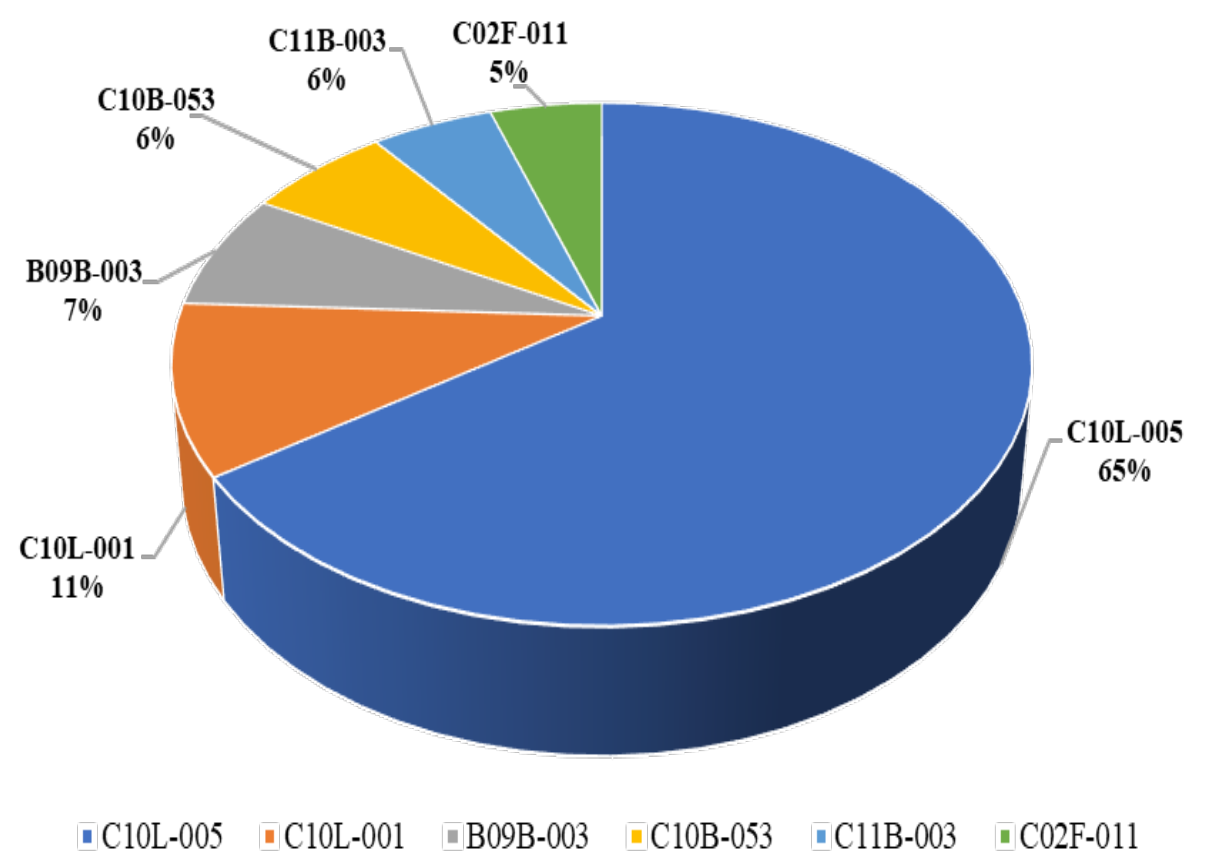

Fonte: Elaborado pelos autores deste artigo com base nos dados obtidos no Derwent, INPI e LATIPAT (2019)

\section{Considerações Finais}

Dado o elevado poder calorífico da borra de café identificado na revisão de literatura e considerando o grande volume de produção e de consumo de café em âmbito mundial, infere-se que a tecnologia para aproveitamento de energias baseada nesse tipo de resíduo tem elevado potencial de aplicação e de retorno econômico, especialmente quando se observa um contexto de recorrente preocupação com questões ambientais e de compromissos assumidos por países em acordos multilaterais.

Entretanto, percebe-se que ainda não há maturidade tecnológica para o aproveitamento da borra de café em escala industrial, haja vista que os resultados da busca em bases patentárias não foram quantitativamente relevantes, com apenas 99 documentos identificados em âmbito mundial, embora houvesse uma quantidade relevante de publicações científicas e notícias divulgadas sobre o uso de borra de café na produção de biocombustíveis. Verificou-se que, nos documentos patentários recuperados nesse levantamento, teve prevalência de ingressos de pedidos no país sul-coreano, sendo a borra do café designada predominantemente para combustível sólido, em especial briquetes.

Verificou-se também que, apesar de a revisão bibliográfica indicar que o desenvolvimento de tecnologias utilizando borra de café na produção de biocombustíveis remonta no Brasil à década de 1960 e de ser ele o maior produtor de café, o número de depósitos patentários (7) no Brasil ou que tenham sido originários dele (1) é incipiente. Resta saber o porquê de esse potencial de aproveitamento não se desenvolver no Brasil, a exemplo do ocorrido com o Programa Nacional do Álcool (Proálcool), criado pelo governo em 1975 para fomentar a produção de bioenergia no país. 
Além disso, havendo a necessidade de se desenvolver soluções para o gerenciamento dos resíduos do setor cafeeiro, as tecnologias de geração de biocombustíveis com uso da borra de café poderiam ser submetidas ao Programa Prioritário de Patentes Verdes ${ }^{5}$ no Brasil, com vistas a acelerar o exame do processo no INPI. Isso poderia fomentar o interesse das empresas, institutos e outros em investir em novas soluções técnicas na área.

Dentre os desafios à adoção desse tipo de tecnologia, vale mencionar os aspectos relacionados à logística reversa, para recolhimento da borra em grande escala. A exemplo do que ocorre com a coleta de óleo de cozinha, tornar-se necessária a estruturação e a coordenação de uma cadeia de suprimentos reversa capaz de coletar, transportar e reaproveitar esse tipo de resíduo (ZUCATTO et al., 2013). Esta é uma atividade que começou a ser adotada pelas empresas que produzem cápsulas de café, as quais ainda destinam a borra coletada somente para compostagem (BABADOBULOS, 2018). Como possibilidades de futuras pesquisas, sugere-se uma análise bibliométrica das publicações sobre o tema e uma análise comparativa das tecnologias contidas nos documentos patentários.

\section{Referências}

ALMEIDA, D. T. L. de; SPAGARINO, G. Estudo da viabilidade de produção de biodiesel a partir de óleo de borra de café extraído com etanol. 2012. Dissertação (Mestrado) - travessão Universidade de São Paulo, Escola Politécnica. São Paulo, 2012.

ASSOCIAÇÃO BRASILEIRA DA INDÚSTRIA DE CAFÉ - ABIC. Consumo mundial de café atinge 165 milhões de sacas no ano cafeeiro 2018-2019. Disponível em: http://abic.com.br/consumomundial-de-cafe-atinge-165-milhoes-de-sacas-no-ano-cafeeiro-2018-2019/. Acesso em: 22 maio 2019.

ASSOCIAÇÃO BRASILEIRA DA INDÚSTRIA DE CAFÉ - ABIC. Estatísticas. Disponível em: http:// abic.com.br/estatisticas/indicadores-da-industria/. Acesso em: 03 dez. 2018.

ASSOCIAÇÃO BRASILEIRA DA INDÚSTRIA DE CAFÉ SOLUVEL - ABICS. Relatório Internacional de Tendências do Café, v. 6, n. 03, 2017.

BABADOBULOS, T. Fabricantes de café em cápsulas intensificaram programas de reciclagem de cápsulas nos últimos anos. Revista Veja, 17 maio 2018. Disponível em: https://veja.abril.com.br/ economia/reciclagem-ainda-e-desafio-para-empresas-de-cafe-em-capsula/. Acesso: 11 out. 2019.

BRANCO, L. G. B. Biocombustíveis brasileiros e o mercado internacional: desafios e oportunidades. Revista CEJ, Brasília, Ano XIII, n. 46, p. 39-48, jul./set. 2009.

BRASIL. Ministério da Agricultura, Pecuária e Abastecimento. Companhia Nacional de Abastecimento - CONAB. Acompanhamento da safra brasileira: café. v. 5, n. 3 (2018). Brasília, 2018.

BRASIL. Ministério da Indústria, Comércio Exterior e Serviços. Instituto Nacional da Propriedade Industrial - INPI. Patentes Verdes. Disponível em: http://www.inpi.gov.br/menu-servicos/patente/ patentes-verdes-v2.0. Acesso em: 30 jan. 2019.

\footnotetext{
${ }^{5} \mathrm{O}$ programa Patentes Verdes tem como objetivo contribuir para as mudanças climáticas globais e visa a acelerar o exame dos pedidos de patentes relacionados a tecnologias voltadas para o meio ambiente. O Programa contempla tecnologias para energia alternativa, transporte, conservação de energia, gerenciamento de resíduos e agricultura (INPI, 2018).
} 
BRASIL. Ministério do Meio Ambiente. Acordo de Paris. Disponível em: http://www.mma.gov.br/ clima/convencao-das-nacoes-unidas/acordo-de-paris. Acesso em: 25 nov. 2018.

CASEIRO, C. A produção e o consumo de biocombustíveis no mundo atual: questões-chave para analisar a sua sustentabilidade. Campo território: revista de geografia agrária, v. 6, n. 12, p. 6-31, ago. 2011.

CAVALCANTI, W. M.; FERNANDES, M. A. Técnicas de uso dos resíduos sólidos de café como agregado para briquetes/péletes e compósitos de madeira. Convibra 2015 Business Conference, 2015.

CONSÓRCIO PESQUISA CAFÉ. Tendências da SIC 2018: Conheça as três principais tendências que ganharam força durante a Semana Internacional do Café de 2018 - e como elas impactam a cafeicultura. Revista Negócio Café, ano 01, n. 04.

CORRÊA, Henrique Luiz; XAVIER, Lucia Helena. Concepts, design and implementation of Reverse Logistics Systems for sustainable supply chains in Brazil. Journal of Operations and Supply Chain Management, v. 6, n. 1, p. 1-25, 2013.

CUNHA, S. et al. Experimento com abacate, borra de café, licuri e leite de coco para extração de óleo, produção de biodiesel e análise expectral. Química Nova, v. 41, n. 6, p. 691-698, 2018.

DENNY, D. M. T. Etanol aquém do Acordo de Paris. Portal Ambiente Legal, 2016.

DIAS, D.; VIAN, C. E. de F.; GRIN, D. Análises de patentes indicam novas tecnologias em biocombustíveis. Revista Visão Agrícola, n. 8, jan-jun 2009.

DURÁN, C. A. A. et al. Café: aspectos gerais e seu aproveitamento para além da bebida. Revista Virtual Química, v. 9, n. 1, p. 107-134, 2017.

DYK, J. S. V. et al. The potential of biofuels in China, China: International Energy Agency (IEA), 2016.

FAO - Food and Agriculture Organization of the United Nations. The state of agricultural commodity markets 2018. Agricultural trade, climate change and food security. Rome, 2018. $112 \mathrm{p}$.

FERREIRA, P. C.; MALLIAGROS, T. G. Investimentos, fontes de financiamento e evolução do setor de infra-estrutura no Brasil: 1950-1996.

FIGINI, H. R. et al. Produção e caracterização do biodiesel obtido a partir do óleo da borra residual de café. In: XXIV Encontro de Química da Região Sul, Florianópolis, 2017.

FORSTER-CARNEIRO, T. et al. Biorefinery study of availability of agriculture residues and wastes for integrated biorefineries. Resources, Conservation and Recycling, v. 77, p. 78-88, 2013.

FUEL CELLS BULLETIN, Korean team uses coffee grounds in direct carbon fuel cell, v. 2015, Issue 9, p. 11, 2015.

JANG, H. et al. Direct power generation from waste coffee grounds in a biomass fuel cell. Journal of Power Sources, v. 296, p. 433-439, 2015.

KOIZUMI, T. The Japanese biofuel program-developments and perspectives. Journal of Cleaner Production, v. 40, p. 57-61, 2013.

KHODAKARAMI, N.; PEREZ, C. N. The Value Chain: a study of the coffee industry. Practical Guide 
to U. S. Transfer Pricing, by William H Byrnes, 3rd ed., LexisNexis, 2016.

KUNRATH, K., et al. Estudo preliminar de nanocompósitos de matriz epoxídica reforçada com negro de fumo. In: Anais [...] 20 ${ }^{\circ}$ Congresso brasileiro de engenharia e ciência dos materiais-CBECIMAT. 2012.

LIMA, D. O.; SOGABE, V. P.; CALARGE, T. C. C. Uma análise sobre o mercado mundial do biodiesel. In:Anais [...] XLVI Congresso da Sociedade Brasileira de Economia, Administração, Rio Branco, 2008.

LOPES, A. C. de P.; ALVES, A. L. C. O mercado cafeeiro no Brasil: um estudo sobre a influência de políticas governamentais nos produtores e exportadores de café da região da Alta Mogiana.

Fórum de Administração, v. 6, n. 1, 2015.

MARICATO, J. de M.; NORONHA, D. P.; FUJINO, A. Análise bibliométrica da produção tecnológica em biodiesel: contribuições para uma política em CT\&I. In: IX ENANCIB - Encontro Nacional de Pesquisa em Ciência da Informação, 2008, São Paulo.

MASIERO, G. Ethanol and Biodiesel: The role of Brazil and South Korea in the emerging alternative energy market. Academic Paper Series, v. 3, n. 10, Dec. 2008.

MATSUMOTO, N.; SANO, D.; ELDER, M. Biofuel initiatives in Japan: strategies, policies, and future potential. Applied Energy, v. 86, p. S69-S76, 2009.

MELO, M. C. de R. e. Políticas públicas brasileiras de biocombustíveis: estudo comparativo entre os programas de incentivos à produção, com ênfase em etanol e biodiesel. 2018. 86f.

Dissertação (mestrado) - Programa de Pós-Graduação em Biocombustíveis, Universidade Federal de Uberlândia.

MENDES, A. P. do A.; COSTA, R. C. da. Mercado brasileiro de biodiesel e perspectivas futuras. In: BNDES Setorial, n. 31, p. 253-279, mar. 2010.

MUSSATO, S. I.; MACHADO, E. M. S.; MARTINS, S.; TEIXEIRA, J. A. Production, composition, and application of coffee and its industrial residues. Food Bioprocess Technol, n. 4, p. 661-672, 2011.

PAGE, J. C.; ARRUDA, N. P.; FREITAS, S. P. Crude ethanolic extract from spent coffee grounds: Volatile and functional properties. Waste Management (2017).

PONCIANO, N. J. Segmento exportador da cadeia agroindustrial do café brasileiro. 1995. 138 f. Dissertação (Mestrado em Economia Rural) - Universidade Federal de Viçosa, Viçosa, 1995.

PRIMAZ, C. T. Valorização de resíduos agroindustriais de café e algodão para produção de bio-óleo e biochar. 2018. 235 f. Tese (Doutorado em Ciências dos Materiais) - Instituto de Química da Universidade Federal do Rio Grande do Sul, 2018.

QIU, H. et al. Liquid biofuels in China: current status, government policies, and future opportunities and challenges. Renewable and Sustainable Energy Reviews, v. 16, n. 5, p. 3.095-3.104, 2012.

ROITMAN, T. Programas internacionais de incentivo aos biocombustíveis e o RenovaBio. Boletim de Conjuntura do Setor Energético - Março/2019. FGV, Rio de Janeiro, 2019.

SALLET, C. L.; ALVIM, A. M. Biocombustíveis: uma análise da evolução do biodiesel no Brasil. Economia \& Tecnologia, ano 07, v. 25, abr./jun. 2011. 
SANTOS, J. N.; HARAGUCHI, D. M. Obtenção do biodiesel a partir de resíduos de café. In: Anais [...] XIX Congresso de Iniciação Científica da Universidade de Mogi das Cruzes. Mogi das Cruzes, 2016.

SILVA, E. M. de P. e; SAKATSUME, F. A política brasileira de biocombustíveis. In: Workshop A expansão da agroenergia e seus impactos sobre os ecossistemas brasileiros. Rio de Janeiro, 2007.

SILVA, V. Valorização de cápsulas de café e produção de biocombustíveis. 2011. $237 \mathrm{f}$.

Dissertação (Mestrado em Engenharia Química) - Instituto Superior de Engenharia do Porto, Porto, 2011.

SU, Y.; ZHANG, P.; SU, Y. An overview of biofuels policies and industrialization in the major biofuel producing countries. Renewable and Sustainable Energy Reviews, v. 50, p. 991-1003, 2015.

SUAREZ, P. A. Z; MENEGHETTI, S. M. P. Assuntos Gerais. 70 aniversário do biodiesel em 2007: evolução histórica e situação atual no brasil. Química Nova, v. 30, n. 8, p. 2068-2071, 2007.

TÁVORA, F. L. História e economia dos biocombustíveis no Brasil. Brasília, DF: Senado Federal, 2011.

TEIXEIRA, M. V. et al. Avaliação da gestão dos resíduos em unidades básicas de saúde de um município sul-brasileiro. Revista de Pesquisa: cuidado é fundamental online, v. 10, n. 3, p. 824831, 2018.

THODE FILHO, S. et al. A logística reversa e a política nacional de resíduos sólidos: desafios para a realidade brasileira. Revista Eletrônica em Gestão, Educação e Tecnologia Ambiental, v. 19, n. 3, p. 529-538, 2015.

VEGRO, C. L. R.; CARVALHO, F. C. Disponibilidade e utilização de resíduos gerados no processamento agroindustrial do café. Informações Econômicas, v. 24, p. 9-16, 2006.

ZUCATTO, L. C.; WELLW, I.; SILVA, T. Cadeia reversa do óleo de cozinha: coordenação, estrutura e aspectos relacionais. Revista de Administração de Empresas, v. 53, n. 5, p. 442-453, 2018.

\section{Sobre os Autores}

\section{Michelle Cristina da Silva}

E-mail: michellemcs.silva@gmail.com

Mestranda em Propriedade Intelectual e Transferência de Tecnologia para a Inovação (PROFNIT).

Endereço profissional: Av. Prefeito Lothario Meissner, n. 632, Jardim Botânico, Curitiba, PR. CEP: 80120-170.

\section{Cassandra Carneiro de Medeiros}

E-mail: cassandramedeiros@yahoo.com.br

Mestranda em Propriedade Intelectual e Transferência de Tecnologia para a Inovação (PROFNIT).

Endereço profissional: Rua Marechal Deodoro, N. 344, $8^{\circ}$ andar, Centro, Curitiba, PR. CEP: 80010-010.

\section{Douglas Alves Santos}

\section{E-mail: dougsaints@gmail.com}

Doutorado em processos químicos e bioquímicos.

Endereço profissional: Av. Prefeito Lothario Meissner, n. 632, Jardim Botânico, Curitiba, PR. CEP: 80120-170. 


\section{Victor Pelaez}

E-mail: victormpelaez@gmail.com

Doutorado em Ciências Econômicas.

Endereço profissional: Av. Prefeito Lothario Meissner, n. 632, Jardim Botânico, Curitiba, PR. CEP: 80120-170.

\section{Fernanda Salvador Alves}

E-mail: fesalves@gmail.com

Doutorado em Administração.

Endereço profissional: Av. Prefeito Lothario Meissner, n. 632, Jardim Botânico, Curitiba, PR. CEP: 80120-170.

\section{Renato Milhomem de Oliveira Filho}

E-mail: rmoliveira17@gmail.com

Graduado em Engenharia Elétrica.

Endereço profissional: Departamento 4, Instituto Federal de Goiás, Campus Goiânia, Rua 75, n 46, Centro, Goiânia, GO. CEP: 74055-110. 